UDC 1(091): 168.3

Hasmik HOVHANNISYAN

\title{
PROBLEMS OF ARGUMENTATION IN MEDIEVAL ARMENIAN PHILOSOPHY
}

\begin{abstract}
None of the medieval Armenian thinkers left a complete piece on argumentation theory. However, argumentation problems and the practical realization of requirements of the theory of argumentation were enormous part of Armenian philosophers' works. They discussed argumentation problems mostly from object-language rather than meta-language prospective.

This research focuses on the works of three mediaeval thinkers: Yeznik Koghbacy (IV-V), David Anhaght (The Invincible, V), Grigor Tatevatsi (XIV-XV). In their theoretical heritage the examination of argumentation issues and coverage can be regarded as the most significant stages of history of Armenian argumentation theories, the interpretation of which first of all aims to accomplish the following problems:

1. Present the argumentation doctrines of each chosen philosopher as a complete idea of the theory of argumentation.

2. Complete the critical analysis of the theoretical heritage of the examinee philosophers.

3. Clarify the most important stages of history of Armenian argumentation doctrines.

4. Thereby increase the possibility of including history of Armenian argumentation theories in universal history.

The history of each theory can be perceived and properly appreciated from the perspective of that theory's modern level of development. Considering that fact this research reconstructs the models of syntax and semantics of the language of argumentation.
\end{abstract}

Keywords: general history of argumentation theories, history of Armenian argumentation theories, Yeznik Koghbacy, David Anhaght (The Invincible), Grigor Tatevatsi, the syntax of the language of argumentation, semantics of the language of argumentation.

Introduction

1. The Importance and Necessity of Analysing the History, Formation and Development of Armenian Argumentation Theories. International conferences and the publications in international professional journals on the theory of argumentation indicate that argu- mentation theorists pay attention to the history of argumentation doctrines. The development of theoretical problems of argumentation cannot be comprehensive without reevaluation of history and without application of the values from the heritage of past to the new theory system. Such studies (see particularly Hovhannisyan, 2005) contribute to the 
publication of general monographic works on the history of argumentation. It is extremely important for such research to include the layers and nuances of the rich traditions of philosophical thought, which deal with the argumentation problems. Otherwise, history of argumentation will be in the same condition as history of logic. Father Bochenski in his fundamental research "History of Formal Logic" only slightly alludes the presence of logical research in Medieval Armenia. (Bochenski, 1961, p. 11). However, the recent Armenian studies show that "David The Invincible's doctorines of the subject of logic and the logic of forms of thought,are one of the important pagesof ancient philosphy. The world history of logical doctrines will significantly suffer if David's theoretical heritage gets ignored." (Brutian; Arevshatyan (eds.), 1983, p. 191).

David the Invincible's logical doctrine is the most crucial phase of the history of Armenian philosophy. Similarly, the analysis of argumentation problems registered in his theoretical heritage is the essential component of the history of argumentation.

This research examines the theoretical heritage of Yeznik Koghbatsy, David Anhaght (The Invincible), Grigor Tatevatsi from the perspective of argumentation. As a result the works of these philosophers are assessed as vital phases in the history of Armenian argumentation.

\section{Comprehension of Argumentation Lan-} guage. Following to the conception of Yerevan School of Argumentation, which is expressed in its founder academician G.Brutians' and his alumnus' works (Brutian, 1992; Brutian, 1993; Brutian, 1998; Hovhannisyan, 2006; Hovhannisyan, 2009; Markaryan, 1986) as well as a basic argumentation model of professors Frans van Eemeren, Rob Grootendorst and Tjark Kruiger (Eemeren, Grootendorst \& Kruiger, 1987)) in this research the theory of argumentation is regarded as a certain language which has its own semantics (the semantics of argumentation language)and syntax (the rules of linking words in argumentation language). The first one includes two substrates: the range of words characteristic for argumentation ("argumentation", "foundation", "proof", "rejection", "conviction", etc.) and the words characteristic for stylistic specifics. The concepts typical to the semantics of argumentation language cannot be observed similarly, since in the process of argumentation they have different meaning and role. The relationship among those concepts can be represented through the following circle scheme:

a) The categories of argumentation

b) The concepts which are not categories, but still are typical of the process of argumentation

c) The concepts typical of a field in epistemology, to which the particular argumentation process refers

d) The concepts taken from the field of sound judgment, essential for the particular argumentation process.

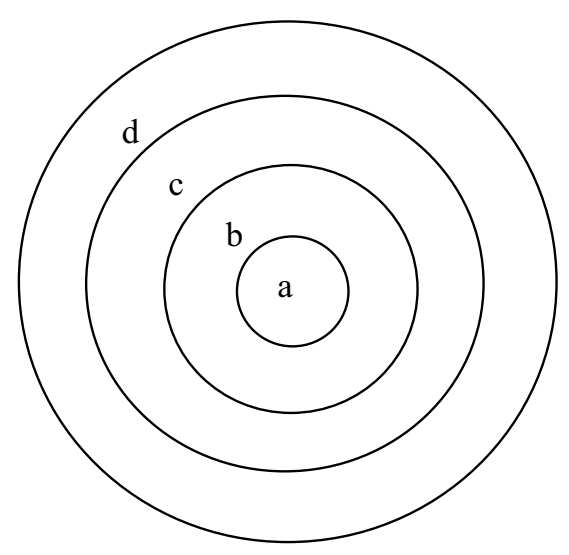


These commentaries refer to the explicit level of argumentation language. Correct comprehension of the implicit level and revelation of the hidden premises are also vital in the process of argumentation. At this point, the role of argumentation language syntax is particularly crucial.

In the process of argumentation, syntax of argumentation language is the multitude of rules referring to the methods of linking words, logical, methodological, psychological, rhetorical, ethical and other skills. In other words, syntax of argumentation language includes the skills of proof, rejection, foundation, persuasion and rhetoric, which are more content wise rather than have formal nature and promote emotional perception and digestion of argumentation among listeners.

The specificity of argumentation is that both its conceptual model and methodological system are not excelling with their innovative structure. Argumentation system contains extrapolated concepts, tricks, principles, patterns from other fields of science (logic, methodology, epistemology, ethics, axiology, psychology, rhetoric and etc.). These concepts are being adjusted and reevaluated from the prospective of new theory - argumentation. As a result, those concepts acquire new meaning and features, which are connected with the goals and issues of argumentation and their interconnectedness.

Conceptual Apparatus of the Argumentation Language in the Viewpoints of Yeznik Koghbatsi, David Anhaght and Grigor Tatevatsi

The primary and basic concepts of semantics model of argumentation were sepa- rated in the selected works, which reflect the specificities, aims and usage of argumentation, as well as the whole explicit and implicit conceptual wealth of argumentation was identified.As a result the following concepts were created:

- field of logical concepts: reasoning, syllogism, argument, anti-argument, acceptable and non-acceptable argument, obvious argument, apparent argument, thesis, antithesis, postulate, proof, foundation, premise, inference, basis, proposition, veracity, division, definition, demonstration, deduction, induction, analogy, analysis, assertion, rejection, deny, disavowal, protestation, objection and etc.

- field of psychological concepts: Conviction, persuasion, conjecture, opinion, authority and etc.

- field of gnoseological concepts: truth, true, correct, exactitude, accuracy, precision, truthfulness, enemy of truth, enemy of justice, veracious, fallacy, misbelief, false, pseudo unjust and inequitable, rejection of recognizability of the world, acceptance of the limitless cogitation, experience as a result of knowledge, the types of knowledge of cognition, limitations of sensory cognition, theory and practice relationship and etc.

- field of ethical concepts: theoretical and practical philosophy, thought and action, goodness and the truth, evil and false, perfect philosopher, goodness, ill, kind, unkind, envy, kind envy, benefit, useless, useful, beneficial, harmful, fit, villain, fair, justice, righteous, worthy, indecorous, will, will and thought, merit, virtue and etc.

- field of the related concepts: conversation, argue, quarrel, debate, discussion, recipient, audience, co-participant, opponent, adherent, supporter and etc. 
The recusntruction of the conecptual aparatus of argumentaion allows to compare conceptual aparatus with modern theories and to identify their historical scientific background through comparative analysis.

Syntactic Methods and Means of Argumentation Language in the Viewpoints of Yeznik

Koghbatsi, David Anhaght and Grigor

Tatevatsi

In order to reconstruct the syntactic model of argumentation language in the works of chosen philosophers this research analysed and classified the methods of argumentation which were used by Armenian philosophers in their "philosophical conversations". After classification, their reasoning regarding the methods and means which form the syntax of argumentation were interpreted utilizing contextual approach.

Armenian philosophers value the following components:

a) Logical methods and means of argumentation

b) Epistemological components of argumentation

c) Axiological components of argumentation

Most of the Armenian philosophers' works are written as a narration, which has very characteristic inner dialogical form. Even the titles of their main writings shows their dialogical character: "Definitions of philosophy by the Trice-Great and Invincible Philosopher David, in Opposition to the Four Propositions of the Sophist Pirrho" (David The Invincible); "The Refutation of Heresies" (Yeznik Koghbatsi); "Book of Questions" (Grigor Tatevatsi) and etc. d) Psychological components of argumentation

e) Rhetorical components of argumentation

f) Ethical components of argumentation

g) Related methods of argumentation

h) Question-answer manifestations.

a) Logical methods and means of argumentation. The research and comparative analysis showcase the preveiling presence of logical concepts in the chosen samples. According to Armenian philosophers the usage of logic, its components, means and principles is the main tool in the process of argumentation.

According to David, a certain discipline and order exists among the logical means. Division precedes definition, definition precedes proof. Analysis is the last one. Proof is the criteria used to differentiate conventional and unconventional sciences. Conventional sciences come from principles that are hungry for proof, but unconventional sciences come from universally accepted principles which do not need proof. Argumentation is an unconventional theory as well from this prospective.

In David's argumentation system proof is combined with assurance, because the aim of "proof" is to "show and assure" that something is the way it is (Anyaght' (David the Invincible), 1980, p. 114).

According to David, throughout argumentation process rejection is applied either for preventing the misunderstandings as a way to prevent possible incorrect interpretations or explanations, or as an inevitable factor for denying the present rejection, in other words double rejection or rejection of rejection.

David the Invincible distinguished two ways of rejection: 1 . Irreconcilable opponent "challenge" method, which aims to oppose true thought to the opponent's provision and 
stubbornly defend it; 2. Equal argument of the opponent's provisions method, in which the antithesis is initially announced and shown true and the consequences of it are showcased as wrong, which proves that the main thesis of the opponent is wrong (Anyaght' (David the Invincible), 1980, p. 81). Debate has chief role in characterization of rejection methods. This fact, testifies the existing difference between the logical and argumentative use of rejection.

Grigor Tatevatsi tells not to limit for good intentions and doing good in the process of argumentation, but also to resist and deny the evil, since originally God gave man three priorities: bright mind, straightforward action and the ability to counterattack the opponent (Tatevatsi, 1740b, p. 223).

Armenian philosophers also value the issue of confirming true provisions: "The ideal argumentation is the one which not only deals with opponent's uncertainty but also is able to confirm the arguer's viewpoints" (Anyaght' (David the Invincible), 1980, p. 37).

Dutch argumentation theorists F.Eemeren, R. Grootendorst \& T. Kruiger claim that rejection and approval of opinions are the primary aims of argumentation. The other aims, such as leaving good impression or gaining the recipients sympathy are secondary, since those can be achieved through other methods as well, whereas rejection and approval can only be realized through argumentation means (Eemeren, Grootendorst \& Kruiger, 1987, p. 5).

According to David, syllogism is also one of the logical methods of argumentation. All sciences, arts and philosophy are in need of syllogism. Theoretical philosophy utilizes syllogism to differentiate between truth and falsehood, whereseas practical philosophy uses it to distinguish good and evil.

David the Invincible differentiates 5 types of syllogism: evidentiary, dialectical, rhetorical, dilettante and poetic. Such differentiation highlights the variances between the logical and argumentative usage of syllogism. Logic limits by evidentiary syllogism. The other types of syllogism are typical of argumentation, since rhetoric exists there.

Yeznik Koghbatsi's Eghts aghandots (Refutation of the Sects) is notable for its wide and various uses of argumentation syntax techniques. It includes nomination and rejection of antithesis (existing or potential), nomination and rejection of counterarguments (existing or potential), demonstration of inconsistency of argumentation, identification of contradictions in opponent's thesis, substantiation based on authoritative opinions, accusation for not considering the authority's (wise) opinion, rejection through referring to authorities, rejection of opinions and viewpoints which are authoritative for the opponent, formulation of thesis at the end of the text (volume) (Koghbatsi, 1994).

b) Epistemological components of argumentation. Interpretation of epistemological components of argumentation first of all comes to evaluation of truth in the works of Armenian philosophers. Truth is the most powerful mean for counter-arguing the opponent in the process of argumentation: "Using turth as our weapon we destroyed the absurd claims of those who tried to deny the existence of philosophy." (Anyaght' (David the Invincible), 1980, p. 37).

Evaluation of truth, rejection of world's imperceptibility, experience as a source of knowledge, types of knowledge, restrictons of 
sensory knowledge, acceptance of infinit ability of knowledge and relationship between theory and practice are all huge part of Armenian philosophers' works.

The opponents of truth create cunfussion, since they do not just come up with empty doubts, but bring up strong and hard to solve problems and rejections (Anyaght' (David the Invincible), 1980, p. 138). Truthful things do not find against each other, whereas false things fight both against each other and the truth (Anyaght' (David the Invincible), 1980, p. 332).

According to Grigor Tatevatsi as well, truth is wise man's weapon and knowledge lightens virtue like the sun. Truth is stronger than anything else in the world, it is honorable, eternal, unreachable and exclusive, but lie is nothing, evil and dishonorable, since "one and only thruth should not follow to numerous lies." Theoretical wisdom starts with speech, but the aim of speech or argumentation is to realize the turth, but the practical mission starts with will and aims to ensure the implementation of truth (Tatevatsi, 1740b, p. 150; Tatevatsi, 1740a, p. 27-28; Tatevatsi, 2003, p. 20).

Tatevatsi's discipline regarding the differentiation of truth and falsehood is significant from the perspective of objectives and requirements of argumentation theory, since "Wise man are more likely to accept and follow disciplines than the senseless" and "Misery to those who will go on teaching the good as evil, and evil as good, the light as darkness and darkness as light" (Tatevatsi, 1740b, p. 281).

It is unique feature of all humans to think that "they are righteous and fair" (Tatevatsi, 2003, p. 70) "the human being is inclined to make mistakes", so Tatevatsi claims "fallacy can only be prevented by wisdom" (Tatevatsi, 1740 b, p. 218). The causes of delusion are sins, which cover the mind like a fog and bring forth blindness of mind and evil's advices (anger, wrath, robbery and etc.), which create mental imbalance, seem kind and righteous (Tatevatsi, 2003, p. 54).

In such situations the need for usage of argumentation becomes more significant. Meanwhile, the aim of argumentation is one, but the methods and ways of realization are many (Tatevatsi, 1740b, p. 216; 224; 307308).

Tatevatsi alerts that the false speech is impure regardless of its size (Tatevatsi, 2000, p. 98). The liar is sentenced and will never be justified, since justification is only possible through confession, and the confession itself is veracity (Tatevatsi, 1740a, p. 27-28). Lie has three ways of expression, through heart, speech and action (Tatevatsi, 1740a, p. 16). Lie can be dangerous, joky, useful (Tatevatsi, 1740a, p. 29).

All manifestations of evil and deception are unacceptable in the process of argumentation. However, in the unjust world it is impossible to avoid evil, fake and wrong speech. The mind is fed both with the good and evil. It is up to the individual which one to choose (Tatevatsi, 2000, p. 136).

The relationship between truth and persuasion is vital in argumentation system. According to the discussed Armenian philosophers, argumentation is a speech directed towards persuasion and truth should be the major tool used in the process of persuasion. From the other hand, they promote type of argumentation which does not limit the recipients' activities and does not impose the truth: 
"People should have free will and freedom of action, since it is unacceptable to compulsory direct people to a right path."

Argumentation also deals with self-criticism, identification of one's own mistakes as well as discussion and analysis of those through various methods. The recipients will have trust only for that kind of fair speaker. Tatevatsi preaches judges to be fearless, wise and incorruptible, as well as he encourages them to judge and correct their own morals and behaviour and only after that pass on judging others (Tatevatsi, 1740a, p. 53).

According to Grigor Tatevatsi, wisdom is preferable than power: the one who has power but no intelligence will be destroyed, whereas the one who has wisdom but no power will rule the world and subordinate enemies. The king survives or wins not due to "its numerous laws", but wisdom, thus he commands: "fight with thought and wisdom." The king should never lie and deceive, since people lie because of weakness and fear, whereas king is powerful and the poor should not strive to be rich but should try to standout with their wisdom." (Tatevatsi, 2000, p. 104; 80).

c) Axiological components of argumentation. Values, value standards and guidelines, usefulness and the issue of substantiating importance have vital role in the argumentation system of medieval Armenian philosopher. Values are links between psychological and ethical factors and elements of argumentation. They regulate psychological and ethical motives of argumentation process. Importance as an evaluation and measure of value plays crucial role in Armenian authors' perceptions of value systems.

The following means stand out in the works of Armenian philosophers: evaluation of opponent's behaviour and position, evaluation of antitheses and contrary viewpoints.

d) Psychological components of argumentation. Non-logical factors are: the demand for combining usefulness and pleasantness, persuasion, formation of opponent's conviction (or recepient's), inner reliance and self-persuasion, authority's opinion "Virtuous and great people do not need rules, whereas they are "rules" themselves for the followers: "Not Plato needs Aristotle's proofs, but Aristotle needs Plato's proofs; not Homer needs Aristotle's poems, but Aristotle needs Homer's poems; not Demostenes needs Hermogenes's arguments, but vice versa." (Anyaght' (David the Invincible), 1980, p. 312). Persuasion is for reasonable, but you do not have to forget about "the ones who are hard to persuade. Do not be lazy and direct persuasion to everyone" (Yeznik Koghbatsi).

Armenian philosphers not only present their attitude towards persuasion but also show that rhetoric and logic work side-byside in the process of persuasion. Rhetoric cannot persuade and will be useless if it is not based on logical means, logical consistency, noncontradictory of mind, in other words truth.

e) Rhetorical Components of Argumentation. Rhetoric is not a part of philosophy, but like grammar, it's a pre-education for it (Anyaght' (David the Invincible), 1980, pp. 34-35; 86). Rhetoric is included in the volume of conviction, but conviction is not rhetoric, since one of the important components of conviction is logical philosophy. Rhetoric cannot convince if it is not grounded on the logic, logical receptions, logical sequence, and logical consistency. David differentiates three types of rhetoric: classical, panegyric and exhortative 
(Anyaght' (David the Invincible), 1980, p. 98).

David the Invincible's understanding of «rhetorical syllogism», that equally includes the lie and the truth, is of great interest (Anyaght' (David the Invincible), 1980, p. 304). All types of syllogism, except the proofing syllogism, include lie, and in the structure of «rhetorical syllogism» the lie and the truth are equal.

The works of Armenian philosophers also excel at the broad use of rhetorical means. Especially, it is necessary to mention the rhetorical question, sudden and unexpected introduction, dialogue (the rhetorician formulates the question and answers it himself), flexibility of thought, clarity of passing thoughts, the choice of the right momment for conclusion, the use of exclamations, appeals and interjections, the right choice of the words, skills to link words, the use of comparisons, personal charm, humility, direct refer to the opponent, inspiration of selfe confidence by referring to the arguments proofing his rightness in the past.

According to the claims of Grigor Tatevatsi the argumentation becomes much audible on the base of four characteristics of speech (kind speech, systemised speech, gentle voice and diplomatic speech). Meanwhile evil, non-accurate, noisy and hurried speech annoys, embarrasses and makes the auditor's thought dogmatic and the argumentation becomes inefficient "the speech remains empty" (Tatevatsi, 1740b, p. 180). The important rhetorical means are also "laconic and charming", courageous, undaunted and true speech (Tatevatsi, 1740b, pp. 211; 309).

f) Ethical Components of Argumentation. In the argumentation system of the observed Armenian philosophers is given an important place to the investigations of the ethical princi- ples and viewpoints. Armenian philosophers analysed in their works Aristotle's ethical doctrine of goodness, "virtuous lifestyle", classification of virtuous, the necessity of the division of philosophy to parts and the issues of the interrelation of theoretical and practical philosophy, goodness and perfect philosopher, goodness and truth, "thought and action", "philosophy and its tool".

David's thoughts on the perfect philosopher are rather remarkable. The perfect philosopher is not the one, who "knows a lot, but the one who has pure lifestyle as givenness and can subdue his passions" (Anyaght' (David the Invincible), 1980, p. 305). The perfect philosopher is characterised by three specific features in the base of which is the demand of ethical upbringing, they are moderate, restrict the passions and desires, not seeking for unachievable things, since unsatisfied yearnings give birth to great sadness (Anyaght' (David the Invincible), 1980, pp. 47; 67).

Discussing the relation between truth and goodness David the Invincible gives privilege to the goodness, that is much more general and comprehensive and in many cases is preferred to the truth. And as the thing that is true is also good, but any good thing is not yet true, sometimes the lie can also be good. In other words, practical philosophy is often preferred to theoretical philosophy (Anyaght' (David the Invincible), 1980, p. 109).

According to Tatevatsi, the theoretical and the practical complement to each other. The practical laws beautify the human thought and soul at the result of which the body becomes beautiful (Tatevatsi, 1740b, p. 280).

Tatevatsi states that the criteria, according to which the goodness and the truth should be differentiated, is the law. There are no small or 
big laws. The law of God and commandments are kept by hearing, learning and then remembering and proofing by actions. The one who keeps the law is awarded and the one who breaks it is punished. Those who know and neglect the law, those who don't know and don't keep the law and those who kept it partially or have forgotten the law that knew before, all of them are profane (Tatevatsi, 1740b, pp. $10 ; 12 ; 38)$.

The guarantee of a true word, kind and fair action is wisdom (Tatevatsi, 1740b, pp. 214; 225). God has granted human beings with free will, so the human being himself chooses the direction of his thought and action. It's impossible and also wrong to make a person to choose virtue. Even God does not command or oblige, he encourages, explains and teaches. This edification is useful for those who deal with argumentation. The virtue is the fulfilment of good by refusing form evil. A human being makes good without knowing about the existence of evil and without rejecting evil consciously, then such action won't deserve praise or glorification. The evil is for a human being to have a chance first to know about and then to reject and refuse it. Tatevatsi warns that one should harry to do goodness, as it's impossible to turn back time, and all the things that seem to be simple and easy today when you are young and lively, will become difficult and impossible tomorrow when you become powerless (Tatevatsi, 1740b, p. 221).

The final aim of argumentation is the fulfilment of certain actions. The neglect of the connection between argumentation and action can lead to a number of extreme conclusions, particularly to the argumentation ending in itself that aims just to convince the recipient. This kind of argumentation is not real and has nothing to do with action and leads to the use of means and methods unacceptable from the viewpoint of the argumentation theory demands. Besides, it cannot be stated by words and not proofed by actions or vice versa to be proved by actions but not stated by words, not taught to others (Tatevatsi, 1740b, p. 281), and a human being is obliged to grow drop by drop within wisdom and acts of virtue (Tatevatsi, 2000, p. 148).

The Armenian philosophers stress the importance of the examination of the question «What for?» or the concept of aim. According to David, the aim with its nature leads to action and supposes the acquirement of not only the supporters but also colleague, as the final condition of aim is the fulfilment. By this understanding of aim is probably conditioned the form of its Old Armenian version 'realisation' and also 'intention' (Anyaght' (David the Invincible), 1980, p. 30). This approach denies those theoreticians of argumentation, who consider the aim of argumentation to be conviction (Perelman \& Olbrechts-Tyteca, 1971) or approval and rejection of opinions (Eemeren, Grootendorst \& Kruiger, 1987).

g) Related Methods of Argumentation. The field of concepts related to argumentation include such concepts, referring to the form of argumentation - dialogue, as: conversation, quarrel, debate, discussion, recipient, coparticipant, opponent, adherent, etc. If the preferable form of argumentation for David the Invincible is "philosophical conversations" (Anyaght' (David the Invincible), 1980, p. 35), then for Grigor Tatevatsi argumentation is a "proverbial speech", that has three specificities, that is to be pleasant for the recipient, to be spectacular and memorable for human being's thought, to brighten the thought and en- 
lighten the commentary of speech (Tatevatsi, 1740 b, p. 304). He states, that the doctrinal rules are schoolings that explain the speech (Tatevatsi, 1740a, p. 5). And the concept "logos" in Old Armenian corresponds with its meaning to the concept argumentation that is obvious form the context. So to the two meanings of the concept "logos" - speech and thought, Tatevatsi adds the third one - argumentation. In case of such approach we can affirm that Tatevatsi differs three types of argumentation: everyday argumentation of a human being (public speech), educational argumentation with the help of proverbs directed to the students (proverbial speech) and opinion (wise speech).

If we assume, that the concepts "speech" and "argumentation" for Tatevatsi are the commensurate concepts and have the same meaning, then it occurs that proverb is an argumentative speech, which according to his demand should refer to the action. Even the criterion to evaluate wisdom is the action: "See how diligent the bee is and learn from him to examine wisdom by labour" (Tatevatsi, 2000, p. 146).

Tatevatsi evaluates proverb as a specific "useful" way to ground the speech, to explain what is said, to fulfil the argumentative act, as because "it is obvious to the favorites and hidden for the foreigners" (Tatevatsi, 2000, p. 14) it is also considered the best way to revel the implicit ways of thought with the help of the explicit ones, as by hearing the bright and obvious examples and arguments a human being is able to reveal the implicit aspects and shades of thought (Tatevatsi, 2000, p. 14). The speech has two sides - known and hidden, just as the well has a depth and surface. He exhorts not to examine what is hidden, but to be satisfied with the examination and cognition of what is known, as when we dig the well that has a surface and go down to its bottom, we lose the water, the same way by examining the depths of the theory that has its surface, we threaten thought and condemn it to be lost. By the way, Tatevatsi warns that a human being seeks for what is invisible as the visible things are temporal and variable, meanwhile, the invisible things are eternal and perennial, so wise and reasonable is the one who can see what is hidden (Tatevatsi, 1740a, p. 101; Tatevatsi, 1740b, pp. 211; 281).

The demand to reveal and examine the context and subtext of argumentation is very important to understand the "invisible" or "hidden" thought and speech, as they are surely not understandable in different auditoriums and depend on the recipient's knowledge, experience, goals, etc. An easily understandable speech or thought can be obtained without any examination, the difficult one by examination, and the non-understandable one is above speech and thought, so it cannot be examined because of non-comprehensiveness and limitedness of our knowledge, therefore, it should be honoured by silence (Tatevatsi, 1740a, p. 280).

Tatevatsi does not aim to keep the humanity from the knowledge of what is implicit, form the revelation of subtext and context, he just tries to prevent the possible mixture of the explicit thought having face, as the same text can have a number of subtexts, the revelation of wheech is not a primitive action.

Tatevatsi also examines the issue of argumentation form. The proverb is a metrical edification that spreads moral virtue that is directed to the children and youngsters. The latters need education and argumentation can 
be used for them as childhood itself is vain and is welcomed that child who listens to the wise man's edification (Tatevatsi, 1740b, pp. 203-204).

The requirements presented to the recipient of the argumentative text, speech are remarkable. The wise speech first of all and amuses the human thought with its beauty. Those who hear wise speech are winners, as they accept and dispose it, and the fools neglect it: "a wise speech that is not followed is a pearl for the laying pigs" (Tatevatsi, 2000, p. 140).

In the works of Armenian philosophers are also used the Related Methods of Argumentation, among which are: to turn to the title of the work, the use of different levels of approach for the discussion of questions, investigation and metainvestigation, explication and presentation with the help of examples, keeping the sequence of the discussion of questions, the importance as a qritarion for the differenciation of the disscuses issues, etc.

h) Question-Answer Manifestations. As the modern theories of argumentation the same way the discussed doctrin of Armenian philosopher's on argumentation become a complete sistem when questioning and question, question-antiarguments, rhetorical questions find their real place in that system. Logic is one of the most important factors of question and answer, of any discussion and dialogue. Probably, with the connection of questioning and logic is explaned the factor that the investigation of the conditions of questions, their structure, correctness of the types, the conditions of regularity is one of the most important isues of the logical component of argumentation, and the interrogative or "question - answer" logic is one of the most important sections of the same theory.

Yeznik Koghbatsi, David the Invincible and Grigor Tatevatsi discuss such issues as the sequence of the questions discussed; the differenciation of the most important question form the important one, and the latter form the secondary one; the use of different levels of approach for the discussion of questions. So David the Invincible explains that Porphyry entitled his work "Introduction", but nor "On Introduction", as the first shows the subject of investigation, meanwhile the title "On Introduction" tells some other things about "Introduction" (Anyaght' (David the Invincible), 1980, p. 116). With this explanation he basically reveals the idea of subject investigation (object-language) and metainvestigation (meta-language) that he uses as means of argumentation.

The "Denial of Sects" is significant from the viewpoint of the controversial rules, development and use of methods and means. The dialogue here is very active and is realised by the exceptional method of questionanswer.

The Armenian philosophers explain by the link of questioning and logic the circumstance, that the investigation of the questions, their structure, types, truth, rules of regularity are the important issues of the logical theory of argumentation, and that the interrogative logic which deals with the investigation of those issues in one of the most important sections of the logical theory of argumentation.

In their works are reflected manifestations of different types of questions that can generally be classified in the following groups:

- Formulation and rejection of a possible question-counterargument.

- Formulation and rejection of an existing 
question-counterargument.

- Range of questions directed straight to the opponent, aiming to reveal the nonsense of the latter's theses.

- Question-thesis that is often formulated at the beginning of the debate over the examined question, and sometimes at the end - as a conclusion.

- Formulation of question and answer that aims just to explain the proposed thesis, the material, containing it.

- Question-foundation directed straight to the reader.

- Question-argument with the help of which the author denies the theses and arguments of the opponent.

During argumentation the level of the recipient's activeness become higher even in the case when the argumentative process is not a dialog in its explicit form, but is fulfilled in the form of monograph. Socrates's questions that need "Yes" or "No" answers, which are shortcomings during an explicit dialog, as they suppose weakening the auditorium's activeness, in case of monograph are not considered as shortcomings as from the viewpoint of a reader-recipient this type of questions is the most acceptable while answering to the questions and thinking about them. In many cases the reader does not notice, or to be more correct, neglect even the fact that the argumentation is directed not only to the authors of the denied viewpoints, but also to him. By the realisation of this circumstance should be explained the often use of this type of questions and the rhetorical questions in the works of the examined Armenian philosophers.
Conclusions

The reflection of the problems of argumentation in the works of Yeznik Koghbatsi, David the Invincible and Grigor Tatevatsi attest that they have their traditions in the history of Armenian philosophy, and that the selected Armenian philosophers in the Armenian reality had their predecessors and successors from the viewpoint of the problems of argumentation, so the investigation of the history of Armenian doctrins is not expired and is not limited by the investigation of the discussed works, and the interpritation of other well-known philosophers' theoretical heritage from the viewpoint of the problems of argumentation can become a subject for other investigations.

\section{REFERENCES}

Anyaght', D. (David the Invincible). (1980). Erkasirut'iwnq p'ilisop'ayakanq, hamahavaq qnnakan bnagrery' \& ar'ajabany' akad. S.S. Arevshatyani (Philosophical Tractats, Joint Critical Natural Texts and Forward by academician S.Arevshatyan, in Armenian). Yerevan: Academy of Sciences Publication.

“Argumentation". An International Journal on Reasoning (ed. Frans H. van Eemeren). ISSN: 0920-427X (print version). ISSN: 1572-8374 (electronic version). Publisher: Springer Netherlands.

Bochenski, I. (1961). A History of Formal Logic. Notre Dame: University Press. 
Brutian, G. (1992). Ocherk teorii argumentatsii (Outline of Argumentation Theory, in Russian). Yerevan: NAS RA Publication.

Brutian, G., Arevshatyan, S. (Ed.). (1983). David Anhakhty - Hin Hajstani Mets Pilisopan (In Armenian). (David The Invinsible - The Grate Philosopher of Aincient Armenia). Yerevan.

Brutian, G. (1993). Logic of Argumentation (The Perelman's View: Pros and Cons Arguments). Bruxelles.

Brutian, G. (1998). Logic, Language, and Argumentation in Projection of Philosophical Knowledge. Lisbon.

Eemeren, F., Grootendorst, R., \& Kruiger, T. (1987). Handbook of Argumentation Theory. Amsterdam: Foris Publication.

Koghbatsi, Y. (1994). Eghts aghandots (Refutation of the Sects, in Armenian). (A.Abrahamyan, Trans. to modern Armenian). Yerevan: YSU Publication.

Hovhannisyan, H. (2005). P'astarkman himnaharcery haj p'ilisop'ajakan mtqi patmut'jan hamateqstum. Girq 1. Yeznik Koghbatsi, David Anhaght, Grigor Tatevatsi (Argumentation Issues in the Context of the History of Armenian Philosophical Thought. Book 1. Three Outlines: Yeznik Koghbatsi, David Anhaght, Grigor Tatevatsi, in Armenian). Yerevan: Publishing House of NAS RA.

Hovhannisyan, H. H. (2006). Language of Argumentation. Journal of Applied Electromagnetism (JAE). Institute of Communication and Computer Systems (pp. 113-123). Athens-Greece.
Hovhannisyan, H. H. (2009). P'astarkman himnaharcery haj p'ilisop'ajakan mtqi patmut'jan hamateqstum. Girq 2. P'astarkman er\&anjan dproc (Argumentation Issues in the Context of the History of Armenian Philosophical Thought. Book 2. Yerevan School of Argumentation, in Armenian). Yerevan: International Academy for Philosophy Press.

Markaryan, E. (1986). Eksplikatsiya kak metod razvitiya yazyka filosofii i ee argumentov (Explication a Method of the Development of the Language of Philosophy and its arguments, in Russian). In G. Brutian, \& I. Narski (Ed.), Philosophical issues of Argumentation (pp. 256-274). Yerevan: Publishing House of NAS RA.

Perelman, C., \& Olbrechts-Tyteca, L. (1971). The New Rhetoric. A Treatise on Argumentation. London: University of Notre Dame Press.

"Philosophy and Retoric" (eds. Patrick Alexander, Director, Teresa Craig, Assistant to the Director. Pennsylvania State University Press.

Tatevatsi, G. (1740a). Girq qarozut'ean, or kochi Amar'an hator (Winter Volum, in Armenian). Constantinople.

Tatevatsi, G. (1740b). Girq qarozut'ean, or kochi D'mer'an hator (Summer Volum, in Armenian). Constantinople.

Tatevatsi, G. (1995). Oskep'orik (Voskeporik, in Armenian). (H.Qyoseyan, Trans.). Yerevan: Gt'ut'jun.

Tatevatsi, G. (2000). Soghomoni ar'akneri meknut'juny. (Commentary on Proverbs of Solomon, in Armenian). (S. Arevshatyan, Forw. and Notes; Kh. 
Grigoryan, Trans.). Yerevan: Ankjunaqar.

Tatevatsi, G. (2003). T'evavor khosqer \& asujt'ner (Proverbs, in Armenian). (S. Grigoryan, Trans. and Forw.) Yerevan: Tigran Mets.
Wahl, J. (1963). Histore de I'argumentation Philosopique. Symposium sobre la argumentation filosofica, (pp. 7-17). Mexico. 